\title{
HistóRIAS DE VIDAS DE PROFESSORES/AS E O FAZER DOCENTE NA SOCIOEDUCAÇÃO
}

\author{
STORIES OF TEACHERS' LIVES AND TEACHING IN SOCIO-EDUCATION
}

DOI: 10.23926/RPD.2526-2149.2020.v5.n2.p1395-1409.id790

\author{
Willian Lazaretti da \\ Conceição \\ Doutor em Educação \\ (Unicamp) \\ Professor na Universidade \\ Federal do Pará (UFPA) \\ lazaretti@ufpa.br
}

\begin{abstract}
Resumo: A educação escolar no âmbito da socioeducação é um dos direitos assegurados aos/às jovens que estão em cumprimento de medida socioeducativa. Essa pesquisa foi realizada com professores/as que trabalham na Fundação Centro de Atendimento Socioeducativo ao Adolescente - Fundação CASA, instituição responsável pela medida de internação no estado de São Paulo. O objetivo é apresentar as especificidades do processo educativo escolar no contexto situado da socioeducação. A história de vida foi utilizada como método e foram entrevistados 12 professores/as que tiveram suas narrativas entrelaçadas com dados provenientes de outras pesquisas. Como resultado é possível verificar que existem aspectos que favorecem o processo educativo se comprado às escolas externas à instituição; número de alunos em sala, relação professor/a - aluno/a e segurança que os/as professores/as sentem. Por outro lado, as classes multisseriadas, o uso restrito de materiais e a rotatividade dos/as adolescentes/as se configuram como fatores que dificultam a ação docente.
\end{abstract}

Palavras-chave: Educação. História oral. Professor. Medida socioeducativa. Privação de Liberdade.

\begin{abstract}
The school education in the context of socio-education is one of the rights guaranteed to young people who are in compliance with a socio-educational measure. This research was carried out with teachers who work at the Fundação Centro de Atendimento Socioeducativo ao Adolescente - Fundação CASA, an institution responsible for the measure of deprivation of liberty in the state of São Paulo. The objective is to present the specificities of the school educational process in the context of socio-education. Life history was used as a method and 12 teachers were interviewed who had their narratives intertwined with data from other research. As a result, it is possible to verify that there are aspects that favor the educational process if purchased from schools outside the institution; number of students in class, teacher-student relationship and security that teachers feel. On the other hand, the multi-grade classes, the restricted use of materials and the adolescents' turnover are configured with factors that hinder the teaching action.
\end{abstract}

Keywords: Education. Oral history. Teacher. Socio-educational measure. Deprivation of Liberty. 


\section{INTRODUÇÃO}

O exercício da docência em escolas públicas possui suas limitações e dificuldades e várias delas já publicizadas em diferentes artigos, dissertações, teses e livros, entretanto o exercício da docência em espaços de privação de liberdade ainda ocupada uma zona de pouca visibilidade (CONCEIÇÃO, 2012, 2013, 2017). Nesse sentido, o presente estudo objetiva apresentar os percursos e percalços que envolvem a prática social da educação escolar para os/as jovens que estão em cumprimento de medida socioeducativa de internação.

Os/as jovens não serão aqui compreendidos/as como "menores", tampouco denominados/as como em "conflito com lei", mas concebendo o/a jovem como sujeito de direito (BRASIL, 1990). Assim sendo, consideramos pertinente a opção pelo termo jovens em situação de restrição e privação de liberdade, pois remete à uma condição temporária, não se trata, pois, de uma condição permanente da perda de liberdade. Tal opção conceitual, pode parecer reducionista ou dotada de eufemismo, mas, constitui-se um dos passos na busca da justiça social (CONCEIÇÃO et al., 2020). Na contramão dessa proposta, estariam aquelas que rotulam os/as jovens como infratores/as, como se esta condição fosse a única possível no decorrer de suas trajetórias. Não obstante os/as menores seriam os/as pretos/as, pobres e moradores das periferias, enquanto os/as adolescentes seriam os/as brancos/as, de classe média/alta e que ao cometer atos infracionais são considerados/as como desviantes de sua conduta tida como "normal".

A Fundação Centro de Atendimento Socioeducativo ao Adolescente - CASA foi instituída por meio da Lei no 12.469, de 22 de dezembro de 2006 (SÃO PAULO, 2006). Ela é uma instituição vinculada à Secretaria de Estado da Justiça e da Defesa da Cidadania, tendo como missão primordial aplicar medidas socioeducativas de acordo com as diretrizes e normas previstas no Estatuto da Criança e do Adolescente (ECA), Lei n ${ }^{\circ} 8.069$, de 13 de julho de 1990 (BRASIL, 1990) e no Sistema Nacional de Atendimento Socioeducativo - Sinase instituído pela Lei Federal no 12.594/2012, de 18 de janeiro de 2012 (BRASIL, 2012).

Ela é responsável pela assistência a jovens de 12 a 21 anos incompletos em todo o estado de São Paulo. Eles/as estão inseridos/as nas medidas socioeducativas de privação de liberdade (internação) e semiliberdade. As medidas - determinadas pelo Poder Judiciário - são aplicadas de acordo com o ato infracional praticado e a idade dos/as adolescentes.

Optamos por considerar a história da infância e da juventude dividida em duas etapas, antes e depois do ECA e, este trabalho adota como recorte a segunda etapa, refletindo sobre o atendimento socioeducativo amparado pelo ECA. Nesse sentido, adotamos como referência o 
entendimento de jovem descrito no segundo artigo do ECA (BRASIL, 1990, s/p.): "considera - se criança, para os efeitos desta lei, a pessoa até doze anos de idade incompletos, e adolescente aquela entre doze e dezoito anos de idade", a opção por utilizar esta definição leva em consideração que todo o atendimento socioeducativo no Brasil é pautado pelo ECA e Sinase.

O artigo 53 do ECA diz que:

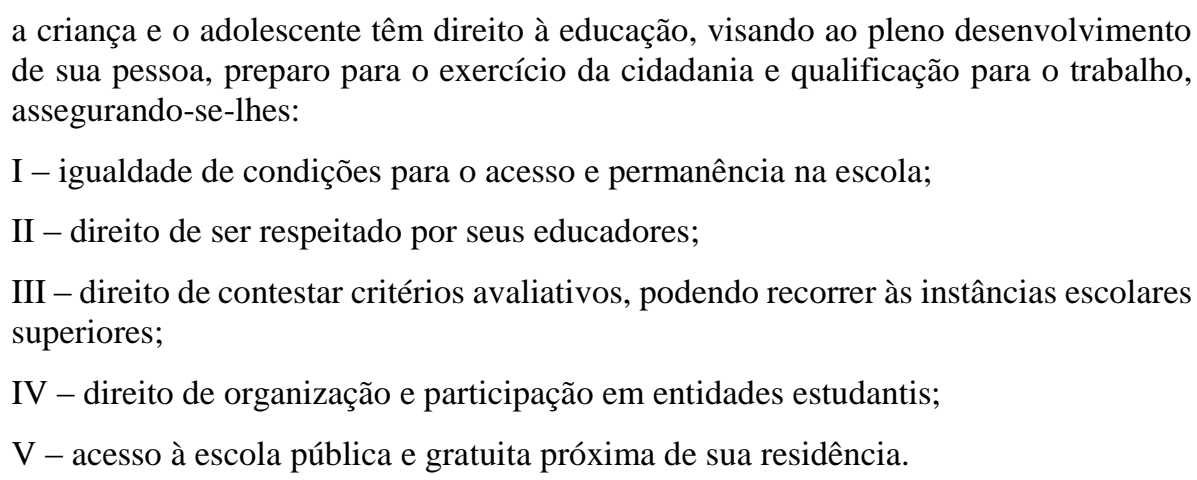

Visando ao atendimento aos artigos anteriormente mencionados, a Fundação CASA criou três superintendências: pedagógica, saúde e segurança. A superintendência pedagógica é responsável pelas áreas da educação escolar, educação profissional, arte e cultura, e educação física e esportes; cada uma dessas áreas possui uma gerência.

A gerência de arte e cultura, responsável pela gestão de convênios, busca encontrar parceiros para a execução das atividades culturais, além de orientar e controlar as ações propostas e desenvolvidas pelos próprios Centros de Internação - CI. Tem por objetivo estabelecer procedimentos visando à organização e padronização e ao controle das ações culturais desenvolvidas no CI e por ele (CONCEIÇÃO, 2012).

A gerência escolar é responsável pelos procedimentos que devem ser realizados para garantir a educação escolar nos CI. Um aspecto interessante é que o quadro de professores não pode ser constituído por professores efetivos, devido à abertura e ao fechamento de salas a qualquer época do ano, conforme a demanda de adolescentes, sua faixa etária e nível de ensino em que se encontram.

A lei do Sistema Nacional de Atendimento Socioeducativo (BRASIL, 2012), em seu artigo oitavo, presume que os Planos de Atendimento Socioeducativo deverão, obrigatoriamente, prever ações articuladas nas áreas de educação, saúde, assistência social, cultura, capacitação para o trabalho e esporte, para os adolescentes. Além de estabelecer como este procedimento deve acontecer. Sendo assim, as Secretarias Estaduais de Educação - SEE são responsáveis pela execução da educação escolar dos adolescentes em situação de privação 
de liberdade, aspecto este que alguns estados já desenvolviam, dentre estes o estado de São Paulo (CONCEIÇÃO, 2013).

A parceria entre as secretarias prevê que a SEE disponibilize uma escola, de preferência, a mais próxima ao $\mathrm{CI}$, para ser a escola vinculadora. Na prática, isso significa que os alunos e professores/as terão seus processos burocráticos - como matrícula de alunos, atribuição de aulas e outros - administrados por ela.

Diante do contexto legal que assegura a educação escolar nos espaços socioeducativos e considerando objetivo dessa pesquisa, nos valemos da história de vida para apontar as especificidades da docência no contexto situado da escola no centro de internação. Cabe esclarecer que há uma opção metodológica que constrói um entrelaçamento entre as narrativas dos/as professores/as com referencial teórico adotado.

\section{REFERENCIAL TEÓRICO}

$\mathrm{O}$ direito à educação deve ser assegurado à essa população, tal como exposto anteriormente, o que buscamos desvelar é como ocorre e quais as especificidades da ação docente no contexto situado da socioeducação. Nas buscas para entender melhor a escola nesse contexto, foi identificada a dificuldade na relação do jovem com o espaço escolar, a qual está a cada dia mais sem "sabor". Os/as professores/as também enfrentam dificuldades no espaço escolar, pois muitas práticas promovidas na escola e por ela não são compreendidas como relevantes pelos/as jovens, de modo que espaço escolar se torna um local de encontro entre amigos/as e não necessariamente espaço para o aprendizado dos conteúdos do currículo escolar (CECCHIA, 2006; DIAS, 2011; QUINELATTO-CAPARRÓS, 2013).

Não adentraremos neste escopo, uma vez que há outros/as pesquisadores/as (VENÂNCIO, 2014; VENÃNCIO et al., 2016) que investigaram sobre a relação da comunidade escolar e o currículo, entretanto não poderia ser desconsiderado, pois este é um dos fatores que contribuem para o jovem se afastar da escola e se aproximar dos atos delitivos (ROLIM, 2014). Aqui nos referimos, predominantemente, ao pobre, negro e de periferia, sem desconsiderar os jovens de classe média e alta que apresentam bom desempenho escolar e também cometem atos infracionais como assassinar indígenas, prostitutas, negros e homossexuais (CONCEIÇÃO, 2017). Ainda temos muito que caminhar para entender o que e como acontece, quais as direções a serem tomadas, uma vez que não acreditamos que seja possível e viável padronizar currículos, posturas e projetos, sem considerarmos a multiplicidade de variáveis e a complexidade de um sistema de ensino num país como o nosso. 
Existem alguns fatores que contribuem para o distanciamento entre o/a adolescente e o espaço escolar que, em alguns casos, são determinantes para que o jovem entre em conflito com a lei (OLIVEIRA et al., 2020). Em pesquisa realizada por Assis (2001) com adolescentes que estavam em conflito com a lei, mais de $70 \%$ dos/as jovens entrevistados/as já haviam abandonado os estudos. As principais alegações dos/as jovens eram a necessidade de trabalhar e a dificuldade de conciliar escola e trabalho, o desentendimento com professores/as e colegas e, ainda, as constantes reprovações, as dificuldades de aprendizagem, instabilidade nas moradias, problemas emocionais e de saúde.

A defasagem no eixo pedagógico interfere também no desenvolvimento dos cursos de educação profissional básica. Utiliza-se esta nomenclatura (educação profissional básica), devido à baixa carga horária e ao espaço físico nem sempre adequado - o qual não conta com todos os recursos necessários a um curso profissionalizante -, característicos desses cursos. Para melhores resultados, seria necessário também que os/as adolescentes já tivessem concluído o ensino médio. Dessa maneira, a qualificação profissional básica ou inicial pode ser um amplo universo de possibilidades de atendimento à população, no que tange à educação para o trabalho e/ou iniciação para o mundo do trabalho.

Em uma pesquisa realizada na cidade de Campinas - SP, Marzochi (2014) buscou o lugar da escola na vida dos jovens que estavam em cumprimento de medida de internação, chegando à conclusão de um não-lugar. Segundo a autora, apesar da escola estar amparada legalmente "os jovens não se identificam com esse lugar devido ao seu caráter disciplinador, embora acreditem que ela possa ajudá-los como trampolim para uma melhora financeira de vida, mesmo a instituição fracassando no cumprimento desse ideal” (p. 150).

Para além desse caráter disciplinador, nota-se que o universo - por muitos, desconhecido - do mundo socioeducativo é cheio de idiossincrasias e, apesar de responderem às mesmas leis, o cotidiano dos CI varia imensuravelmente entre eles, desde o trato ao jovem até aos processos corriqueiros do dia a dia. Por essa razão, o olhar direcionado a esse espaço deve ser múltiplo e ao analisarmos diferentes pesquisas realizadas em espaços controversos, é possível evidenciar diferenças e as variações entre práticas sociais e processos educativos em cumprimento de medida socioeducativa de internação.

Diante desse contexto e suas implicações, Lopes (2006) pesquisou a prática social da educação escolar de adolescentes em situação de privação de liberdade, identificando que a escola regular de um CI tem suas limitações aumentadas, tendo em vista o conjunto das regras da própria instituição, além de possuir estrutura rígida e caráter violento. Desse modo, podemos 
refletir o quanto um currículo elaborado "de fora" e para "outra realidade" pode comprometer os processos educativos por não considerar as especificidades do cenário em questão.

Para Marzochi (2014), os/as professores/as dentro da Fundação CASA se despem da postura disciplinar que a escola regular possa exigir deles/as, tendo em vista que lá dentro esta responsabilidade fica a cargo dos/as agentes de apoio socioeducativo (seguranças), contribuindo assim para que seja possível à maioria deles/as reinventar suas relações com os/as jovens, promovendo um contato mais afetivo, tratando os/as alunos/as com mais respeito, diferenciando-se daqueles/as profissionais que desenvolvem seu trabalho fora da Fundação, muitas vezes com ideal disciplinador.

As professoras Cilene e Abenilda, colaboradoras da pesquisa, concebem essa relação por outra perspectiva, por estarem em outra posição e em outro Centro de Internação. Em suas narrativas discordam que o trabalho na Fundação não requer que os/as professores/as se posicionem firmemente e/ou cobrem posturas adequadas dos/as jovens, delegando essa função aos/às agentes de apoio socioeducativo. Cilene relatou as discussões que já teve com jovens impondo-se, e pedindo respeito, respeito este adotado como premissa para a sua permanência em sala de aula. Abenilda, por sua vez, relata que certa vez saíra correndo atrás de um jovem que queria se esconder em outra sala; a professora fora atrás dele para que voltasse à sala.

Há uma especificidade no contexto socioeducativo que exige que o/a professor/a se posicione, ainda que contra a sua vontade, sobre o lado que ocupará nas relações de poder. Se optará pela parceria com a segurança, sendo chamado/a pelos/as alunos/as como 'arrastão' (OLIC, 2017), aquele que se imbui de ações opressoras e autoritárias, ou então buscará criar vínculo com os/as jovens, dando maior liberdade a eles/as de se expressarem e promovendo um espaço educativo pautado no diálogo.

O que se passa nesses casos é que a rotina e a dinâmica estabelecidas no cotidiano dos CI variam conforme os profissionais que compõem cada um destes espaços de disputa de poder, pois dependem da perspectiva adotada pela direção, equipe psicossocial, educadores/as, seguranças, famílias e, claro, os/as próprios/as adolescentes. O que queremos dizer é que existem modelos extremamente repressivos e hostis, nos quais o/a adolescente deve andar com a cabeça baixa, mãos para trás, seguir linhas demarcadas no chão e pedir licença para cada funcionário/a que passar, mas outros modelos são possíveis e, quando do uso deles, o diálogo é soberano e o objetivo é promover a reflexão desses/as adolescentes sobre a conduta infracional que tiveram para que consigam traçar novos rumos para a vida. 


\section{Metodologia}

Os dados analisados neste estudo advêm da pesquisa realizada no doutoramento realizado no Programa de Pós-Graduação em Educação da Universidade Estadual de Campinas - Unicamp. O caminho metodológico se dá pelos princípios da História Oral, tendo como base os autores Meihy (1996), Caldas (1999), Guimarães (2011), Meihy e Holanda (2013). A história oral utilizada enquanto um método faz com que as histórias de vida sejam o epicentro do trabalho.

A comunidade de destino ${ }^{1}$ constitui-se com professores que à época, lecionavam na Fundação CASA, e a colônia ${ }^{2}$ os/as vinculados/as a um complexo de internação em um município da região metropolitana do estado de São Paulo. Foram convidados/as doze docentes os/as quais enquanto profissional atuante nesse espaço, já tinha uma relação estabelecida que seria necessária ao processo de colaboração.

O sentido de colaboração aqui proposto não percebe as pessoas como objetos de estudo, mas como propõe Oliveira et al. (2014) são participantes da pesquisa que co-laboram com a investigação realizada. Ainda sobre o uso do termo colaboração nesta pesquisa, trazemos a contribuição de Meihy e Ribeiro (2011), pois no caso da história oral o/a interlocutor/a está no centro gerador de visões, ele/a transcende o papel ou função de fornecedor/a de dados, de transmissor/a de informações, isso não significa, porém, que entrevistador e entrevistado/a tenham o mesmo trabalho, mas que ambos são sujeitos ativos e tem como propósito a elaboração de um saber.

O vínculo fraterno estabelecido entre pesquisador com a maioria dos/as colegas ao longo dos anos de trabalho colaborativo na socioeducação facilitou a incorporação de requisitos éticos sobre os quais Portelli (2012) discorre:

compromisso com a honestidade significa, para mim respeito pessoal por aqueles com quem trabalhamos, bem como respeito intelectual pelo material que conseguimos; compromisso com a verdade, uma busca utópica e a vontade de saber "como as coisas realmente são", equilibradas por uma atitude aberta às muitas variáveis de "como as coisas podem ser" (PORTELLI, 2012, p.15).

Em relação à ética e ao respeito aos/às colaboradores/as consideramos as preocupações expostas por Denis (2008), tais como analisar os riscos e as contribuições do projeto, respeitar a cultura das pessoas e as formas de abordagem; para o autor, os contatos prévios determinam a qualidade de todo o processo: a apresentação dos objetivos da pesquisa, do termo de

\footnotetext{
${ }^{1}$ Nesse caso a comunidade de destino poderia ser entendida como todos/as os/as professores/as que lecionavam a Fundação CASA.

${ }^{2}$ Compreendendo os/as que tinham vinculo com o complexo mencionado.
} 
consentimento livre e esclarecido e do termo de cessão, que serviu para verificar se os colaboradores desejariam ser ou não identificados e se permitiriam o uso de suas imagens.

Das narrativas dos/as doze professores/as convidados/as emergiram experiências de vida próximas entre eles/as, atravessadas pela etnia (raça negra, branca e povo indígena), notadamente a classe pobre e em algumas infâncias beirando a miséria, a criação em cidades afastadas das grandes metrópoles, o abandono tanto paterno quanto materno, o trabalho infantil, a violência doméstica, as diferentes formas de preconceitos, sobretudo no que tange à relação com a linguagem característica da região nordeste do Brasil e o início de carreira como docente na Fundação CASA. Trajetórias singulares que culminaram no encontro de subjetividades no ato de ensinar e aprender com os/as jovens em um espaço de educação e punição.

\title{
4 Resultados E discuSSÃo
}

A educação escolar para jovens em situação de privação de liberdade, acontece em meio a um turbilhão de emoções, debates, resistências e disputas. Na pesquisa realizada por Costa Junior (2012), a qual acompanhou o processo de (re)definir qual seria o modelo "pedagógico" que o Centro de Internação o qual estava inserido adotaria como base para as demais ações educativas, a saber: se continuariam deixando os jovens mais "livres" ou se deveriam optar por um modelo que segue uma linha radicalmente disciplinadora. $\mathrm{O}$ autor e professor do ensino formal, quando questionava os jovens a respeito da escola no "mundão"; recebeu respostas denotando o desinteresse pelo processo educacional-escolar.

\begin{abstract}
O espaço escolar no mundão é apenas mais um local onde a maioria deles estendem suas sociabilidades com o intuito de flertar com "as novinhas", "tumultuar" com os "parceiros" e, em alguns casos, manter ativos seus negócios ilícitos (venda de drogas) ou organizar e programar os possíveis furtos e assaltos. Raros são os casos em que um adolescente me relata que ia à escola para estudar. Mesmo nesses casos, ainda diziam que a sociabilidade com "as novinha" era um motivador a mais para estarem naqueles locais. Nenhum dos relatos demonstrava a preocupação deles em estudar para ter uma formação apropriada para exercer alguma atividade profissional (COSTA JÚNIOR, 2012, p. 124).
\end{abstract}

O relato do professor-pesquisador vai ao encontro dos relatos dos jovens entrevistados por Marzochi (2014), quando se referem ao sentido da escola antes do cumprimento da medida e como percebem a prática social escolar em privação de liberdade, como é possível ver no relato do adolescente identificado como Bruno.

Eu não sentia a escola na minha vida, sei lá, não queria fazer tarefa, só bagunçar, ficava com preguiça. Mas, depois que eu vim para cá eu comecei a me interessar mais, me esforçar mais, comecei a ver que daqui em diante minha vida seria ser isso que sou hoje (...) Aqui dentro eu tenho uma professora que me ajuda bastante. Eu vejo que 
ela é uma boa professora, me ajuda, tem interesse em desempenhar um bom trabalho (...) (MARZOCHI, 2014, p. 90).

O sentimento compartilhado por Bruno se associa em dois momentos ao relato da professora Luiza. No primeiro, quando a professora é alertada por colegas que lecionam nas escolas estaduais, em relação à dificuldade em conseguir desempenhar um bom trabalho. No segundo momento, quando a professora nos diz que às vezes alguns/as alunos/as apresentam dificuldades e começam a se calar em sala, dispersando a atenção, mas, ao perceber tal conduta, Luiza busca outras formas de ensinar, conversando com o/a adolescente para entender a raiz da dificuldade, a qual muitas vezes consiste em conteúdos relacionados às series anteriores que não foram devidamente apreendidos por esses/as jovens.

Kel foi um dos jovens entrevistados por Scolaro (2007) e descrito como um garoto baiano de cor preta, triste, de 19 anos. Segundo a pesquisadora, o jovem relatou que foi apreendido pela primeira vez com 13 anos e que a escola antes da privação de nada lhe serviu; o garoto a frequentava de modo irregular desde que começou a "cheirar cola".

\begin{abstract}
Não gostava da escola, não gosto de ir pra escola. Não... Me chamou de cheira cola, não tem nada a ver... Toma conta da vida dela, deixa a dos outros. Um dia ela dava conselho, outro ela reclamava. "Seu cheira cola... não sei o quê...não sei o quê... Eu já falei com você pra sair dessa vida. Se não sair, vai ser expulso." Outro dia: "Rapaz, não cheira cola não, faz mal... Obedeça a sua mãe". Ficava nesse aí. Falava pra eu parar de cheirar cola, estudar mais, aprender pra passar na série, pra quando eu crescer, virar "gente", não ficar sem ninguém... que eu ia ser um ladrão morto, como todos morrem por aí. A escola pra mim não serviu pra nada. Na escola, só aprendi fazer meu nome (SCOLARO, 2007, p. 48).
\end{abstract}

Nesse contexto a professora era uma mistura de ajuda com preconceito, em certos momentos era calma e tentava aconselhar o Kel para que buscasse outra forma de viver, mas, ao mesmo tempo se utilizava de formas repressivas como a possibilidade de expulsão, os rótulos de "cheira cola", "nóia" e outras expressões pejorativas.

Dias (2007), Gallo e Williams (2005, 2008) e Dias (2011) identificaram aspectos semelhantes em suas pesquisas, quando relatam que os/as professores/as são apontados/as como parte integrante de discriminação, segregação e falta de atenção ao/à jovem que apresenta dificuldade no processo educacional-escolar. Como resultado, alguns/mas alunos/as criam ou adotam movimentos de resistência, perpetuando formas violentas de lidar com a situação vivenciada.

O cometimento de atos de indisciplina é, para o adolescente, o início da visibilidade na escola em que não aprende. É também o caminho para o envolvimento com o ato infracional. Assim, a violação de direitos do adolescente inicia com a não aprendizagem e se acentua nas demais relações familiares e sociais que o adolescente possui. Assim, a contradição existe no fato de que a não aprendizagem não é um 
condicionante para o olhar escolar, enquanto a indisciplina é (ZANELLA, 2010, p. 13).

Desenvolver ações pedagógicas com os adolescentes marginalizados/as não é tarefa fácil, devido à grande defasagem escolar causada pelo distanciamento que sofrem com as diversas maneiras que a sociedade e a escola promovem para mantê-los/as afastados/as e silenciosos/as.

Scolaro (2007) nos apresenta a Danda, uma jovem cearense que foi ainda criança para Salvador, bonita, de 17 anos, parda, alegre e que se emocionava facilmente.

Cheguei a estudar em escola particular e escola pública, mas eu acho que o ensino da escola pública, comparado com o da escola particular, tem uma diferença. Na escola pública, você não é tão observada como é na escola particular. Na escola pública, os alunos de lá me ensinavam a brigar, a ir pra festa, a resmungar com a minha mãe, coisas que fizeram eu perder muito. Eu perdi ela por isso (SCOLARO, 2007, p.57).

Danda nos mostra sua percepção sobre o espaço escolar público e o quanto o convívio com as/os jovens nesse ambiente atrapalhou o seu relacionamento familiar, bem como a dificuldade da equipe pedagógica em dar atenção a todos/as os/as alunos/as como aconteceu com ela quanto teve a oportunidade de estudar em colégio privado.

A professora Carla relata que já teve de ensinar jovens a ler e que se sente muito feliz por cada conquista desses/as jovens. Da mesma forma, também a professora Cilene menciona que esse foi um dos primeiros desafios a superar quando iniciou o trabalho com adolescentes em situação de privação de liberdade. Estavam todos misturados - adolescentes que sabiam e outros que não sabiam escrever o próprio nome -, então a professora levou os livros de seu filho para alfabetizar os que necessitavam, trabalhando com múltiplas realidades numa mesma sala de aula, tendo em vista que as classes são multisseriadas com alunos/as de diferentes idades e níveis educacionais.

\footnotetext{
Meu primeiro desafio foi quando eu deparei com um adolescente de 17 anos que não sabia ler nem escrever nem o próprio nome. E eu queria fazer alguma coisa para ele aprender a escrever o nome, detalhe ele estava matriculado na $6^{\mathrm{a}}$ série como pode um adolescente de 17 anos sem saber ler e escrever? Meu filho estava na $1^{\text {a }}$ série, então eu tirei cópia do livro de alfabetização e levei. Combinei que entre uma atividade e outra da turma eu sentaria e explicaria para ele, falei que ensinaria com o método que eu sabia misturado com o livro, por que eu fui alfabetizada com Caminho Suave (CONCEIÇÃO, 2017, p.33).
}

A classe multisseriada é alvo de crítica das professoras Carla, Neuda e Sinhá que relatam que dependendo do CI em que estão, a situação fica mais complexa, pois não permitem que se façam trabalhos inovadores utilizando outros recursos que não apenas giz, lousa e saliva. Não 
obstante, ainda é obrigatório o uso do caderno do aluno ${ }^{3}$ com alunos/as de diferentes anos. A professora Carla relata:

Se eu pudesse, mudaria esse sistema de classes multisseriadas. Porque o professor, principalmente no começo fica de mãos atadas. O currículo é outro aspecto que é muito difícil. O professor dentro da Fundação tem que trabalhar o currículo do governo, das escolas daqui de fora. Não tem como você entrar numa sala de aula com quatro livrinhos de diferentes séries/anos do currículo, é humanamente impossível (CONCEIÇÃO, 2017, p.34).

Em pesquisa realizada em 1995 e 1996, Volpi (2006) verificou que do montante de 4.245 adolescentes privados de liberdade, 96,6\% não haviam concluído o ensino fundamental, o índice de não alfabetizados era de $15,4 \%$ e apenas sete adolescentes haviam concluído o ensino médio. A pesquisa de Volpi aponta, ainda, que $61,2 \%$ dos adolescentes não frequentavam a escola quando cometeram o ato infracional. Estes dados evidenciam a existência de situações que operam no distanciamento do/a adolescente com a prática social escolar.

\section{CONSIDERAÇÕES FINAIS}

A relação professor/a - aluno/a, é permeada pelo estigma com falas preconceituosas que se tornam fatores de risco; necessitamos direcionar o olhar para a formação inicial e a responsabilidade de trazer estes temas ao debate, justamente para criar esse conflito antes durante a formação inicial -, e não depois de inseridos/as nas escolas. São inquietações que pretendem provocar aos/às professores/as que estão no cotidiano escolar a refletirem sobre suas práticas, revisitando posturas de modo a evitarem a reprodução de ações preconceituosas para com alunos/as, ações estas que corroboram e acentuam o cenário de injustiça social presente no país (CONCEIÇÃO et al., 2020).

A educação escolar para jovens no contexto socioeducativo tem a relação professor/a aluno/a ressignificada mediante as especificidades existentes no cotidiano desses/as jovens. Os estigmas que sofreram antes de entrar em conflito com a lei, passam a não ser considerados quando em cumprimento de medida, ao menos na realidade do contexto das pesquisas entrelaçadas nesse trabalho. Os/as professores/as mostram-se dispostos/as a ensinar, pois reconhecem as dificuldades que os/as jovens já enfrentaram (e ainda enfrentam) no processo escolar.

\footnotetext{
${ }^{3}$ Material seriado elaborado como parte do material didático aos alunos da rede estadual de educação do estado de São Paulo. Os cadernos são distribuídos aos alunos e correspondem ao ano em curso.
} 
A discrepância entre idade e ano que os/as jovens chegam é notória e se agrava com a falta de um debate específico sobre um currículo que contemple as especificidades do atendimento socioeducativo, que considere as implicações da ações que prezam pela segurança, dos impactos de estarem distantes da família, das múltiplas violências que já vivenciaram (e vivenciam). A proposta de um currículo conteudista não se aplica a essa realidade, sobretudo com a rotatividade dos/as adolescentes em cumprimento de medida de internação, a qual alguns/mas permanecem três meses enquanto outros/as três anos.

Enquanto alguns estudos se debruçam sobre práticas punitivas que não sejam privativas de liberdade, evitando o encarceramento em massa, outros temas merecem atenção por parte da universidade e do poder público, tal como: o que se pretende ensinar na educação escolar aos/às jovens em cumprimento de medida socioeducativa de internação? Se resumiria a uma proposta conteudista, a uma sistematização de conteúdos? Quais as relações são estabelecidas entre escola e os/as adolescentes que têm a extinção da medida de internação?

Insta deixar algumas provocações que ainda merecem um olhar acurado no âmbito da socioeducação e que foram superficialmente trazidos neste texto, mas que necessitam de outras pesquisas, tais como as relações étnico-raciais e a diversidade de gênero e como essas implicações estão ou não presentes no currículo escolar.

\section{REFERÊNCIAS}

ASSIS, Simone Gonçalves; CONSTANTINO, Patrícia. Filhas do mundo: infração juvenil feminina no Rio de Janeiro. Rio de Janeiro: Fiocruz, 2001.

BRASIL. Lei n. ${ }^{\circ} 8.069$ de 13 de julho de 1990. Dispõe sobre o Estatuto da Criança e do Adolescente e dá outras providências. Disponível em:

http://www.planalto.gov.br/ccivil_03/leis/18069.htm. Acesso em 26 jun. 2020.

BRASIL. Lei $\mathbf{n}^{\mathbf{0}}$ 12.594, de 18 de Janeiro de 2012. Esta Lei institui o Sistema Nacional de Atendimento Socioeducativo (Sinase) e regulamenta a execução das medidas destinadas a adolescente que pratique ato infracional. Disponível em:

http://www.planalto.gov.br/ccivil_03/_Ato2011-2014/2012/Lei/L12594.htm. Acesso em 26 jun. 2020.

CALDAS, Alberto Lins. Oralidade, texto e história: para ler a história oral. São Paulo: Edições Loyola, 1999.

CHECCHIA, Ana Karina Amorim. O que jovens alunos de classes populares têm a dizer sobre a experiência escolar na adolescência. 2006. 234f. São Paulo: Dissertação (Mestrado em Psicologia da Educação) - Universidade de São Paulo, São Paulo, 2006. Disponível em: https://www.teses.usp.br/teses/disponiveis/47/47131/tde-03082006-

212144/publico/Checchia_tde.pdf. Acesso em: 20 jun. 2020. 
CONCEIÇÃO, Willian Lazaretti da. Lazer e adolescentes em privação de liberdade: um diálogo possível? 2012. 145f. Dissertação (Mestrado em Educação) - São Carlos:

Universidade Federal de São Carlos, 2012. Disponível em:

https://repositorio.ufscar.br/bitstream/handle/ufscar/2630/4535.pdf? sequence=1\&isAllowed= y. Acesso em: 20 jun. 2020.

CONCEIÇÃO, Willian Lazaretti da. Escola e privação de liberdade: um diálogo em construção. Revista Brasileira Adolescência e Conflitualidade, v. 02 (9), 2013, p.72 - 88. Disponível em: https://revista.pgsskroton.com/index.php/adolescencia/article/view/235/0. Acesso em: 20 jun. 2020.

CONCEIÇÃO, Willian Lazaretti da. Histórias de vidas que se unem: a professora, o professor e os [elos com os] jovens infratores. 2017. 136 p. Tese (Doutorado em Educação) Campinas: Universidade Estadual de Campinas, 2017. Disponível em:

http://www.repositorio.unicamp.br/handle/REPOSIP/322308. Acesso em: 20 jun. 2020.

CONCEIÇÃO, Willian Lazaretti da; TEIXEIRA, Joana Darc.; CAMPOS, Rafael Garcia. Socioeducação. Olhares: Revista do Departamento de Educação da Unifesp, v. 8, n. 2, p. 102-121, 9 ago. 2020. Disponível em:

https://periodicos.unifesp.br/index.php/olhares/article/view/10625 Acesso em: 22 ago. 2020.

COSTA JUNIOR, Reinaldo Vicente. Tá em casa ou na escola? Uma leitura da prática escolar em unidade de internação socioeducativa da cidade de São Paulo. 2012. 181f. São Paulo: Dissertação (Mestrado em Educação) - Universidade Nove de Julho, São Paulo, 2012. Disponivel em:

https://bibliotecatede.uninove.br/bitstream/tede/511/1/B_Reinaldo\%20Vicente\%20da\%20Cos ta\%20Jr.pdf. Acesso em: 26 jun. 2020.

DENIS, Philippe. A ética da história oral na África do Sul. Oralidades: Revista de História Oral, ano 2, n. 3, p. 47 - 63, jan-jun, 2008.

DIAS, Aline Fávaro. O jovem autor de ato infracional e a educação escolar: significados, desafios e caminhos para a permanência na escola. 2011. 169f. São Carlos: Dissertação (Mestrado em Educação) - São Carlos: Universidade Federal de São Carlos, 2011. Disponível em:

https://repositorio.ufscar.br/bitstream/handle/ufscar/2580/3560.pdf? sequence $=1 \&$ isAllowed= y. Acesso em: 26 jun. 2020.

GALLO, Alex Eduardo.; WILLIAMS, Lúcia Cavalcanti de Albuquerque. A escola como fator de proteção à conduta infracional de adolescentes. Cadernos de pesquisa, v. 38, n. 133, p. 41 - 59, 2008. Disponível em: https://www.scielo.br/scielo.php?pid=S010015742008000100003\&script=sci_abstract\&tlng=pt Acesso em: 20 jun. 2020.

GALLO, Alex Eduardo; WILLIAMS, Lúcia Cavalcanti de Albuquerque. Adolescentes em conflito com a lei: uma revisão dos fatores de risco para a conduta infracional. Psicol. teor. prat., v.7, n.1, p.81 - 95, 2005. Disponivel em:

http://pepsic.bvsalud.org/scielo.php?script=sci_arttext\&pid=S1516-36872005000100007. Acesso em: 20 jun. 2020. 
GUIMARÃES, Aurea Maria. Vidas de jovens militantes. 2011. 416f. Campinas: Tese (Livre Docência) - Campinas: Universidade Estadual de Campinas, 2011. Disponivel em: http://repositorio.unicamp.br/bitstream/REPOSIP/322742/1/Guimaraes_AureaMaria_LD.pdf. Acesso em: 20 jun. 2020.

LOPES, Juliana Silva. A escola na FEBEM - SP: em busca do significado. 2006. 161f. Dissertação (Mestrado em Psicologia) - São Paulo: Universidade de São Paulo, 2006. Disponivel em: https://www.teses.usp.br/teses/disponiveis/47/47131/tde-09042007153821/publico/Dissertacao.pdf Acesso em: 20 jun. 2020.

MARZOCHI, Andrea Souza. História de vida dos jovens da Fundação Casa: o lugar da escola nessas vidas. 2014. 188f. Dissertação (Mestrado em Educação) - Campinas: Universidade Estadual de Campinas, 2014. Disponível em: http://repositorio.unicamp.br/jspui/bitstream/REPOSIP/254093/1/Marzochi_AndreaSouza_M. pdf Acesso em: 20 jun. 2020

MEIHY, José Carlos Sebe Bom. Manual de História Oral. São Paulo: Ed. Loyola, 1996.

MEIHY, José Carlos Sebe Bom.; HOLANDA, Fabiola. História oral: como fazer, como pensar. $2^{\text {a }}$. ed. São Paulo: Contexto, 2013.

MEIHY, José Carlos Sebe Bom; RIBEIRO, Suzana Lopes Salgado. Guia prático de história oral: para empresas, universidades, comunidades, famílias. São Paulo: Contexto, 2011.

OLIC, Mauricio Bacic. Arrastão ou lagarteado? Dinâmicas em torno da prática docente na Fundação CASA. Educ. Pesqui., São Paulo, v. 43, n. 2, p. 357-377, abr. 2017. Disponível em: https://doi.org/10.1590/s1517-97022016133882. Acesso em: 26 jun. 2020.

OLIVEIRA, Maria Waldenez; SILVA, Petronilha Beatriz Gonçalves e; GONÇALVES JUNIOR, Luiz; MONTRONE, Ainda Victoria Garcia; JOLY, Ilza Zenker Leme. Processos educativos em práticas sociais: reflexões teóricas e metodológicas sobre pesquisa educacional em espaços sociais. In: OLIVEIRA, Maria Waldenez; SOUSA, Fabiana Rodrigues. Processos educativos em práticas sociais: pesquisas em educação. São Carlos: EdUFSCar, 2014. p. 29 $-46$.

OLIVEIRA, Ueliton Peres de; CONCEIÇÃO, Willian Lazaretti da; GRUNNENVALDT, José Tarcísio; OLIVERA, Raul Angel Carlos; REVERDITO, Riller Silva. Esporte e lazer no plano individual de atendimento de adolescentes em cumprimento de medida socioeducativa de internação. Movimento (ESEFID/UFRGS), Porto Alegre, p. e26054, jul. 2020. ISSN 19828918. Disponível em: https://seer.ufrgs.br/Movimento/article/view/101588. Acesso em: 22 ago. 2020.

PORTELLI, Alessandro. Tentando aprender um pouquinho: Algumas reflexões sobre a ética na História oral. Projeto História: Revista do Programa de Estudos Pós-Graduados de História, [S.1.], v. 15, set. 2012. Disponível em: https://revistas.pucsp.br/revph/article/view/11215/8223 Acesso em: 26 jun. 2020.

QUINELATTO-CAPARRÓS, Rubia Fernanda. Entre saberes, sabores e desafios da tarefa educativa com jovens em conflito com a lei: como as educadoras significam os processos educativos do espaço do programa de medidas socioeducativas em meio aberto. 2013. 174f. 
Dissertação (Mestrado em Educação) - São Carlos: Universidade Federal de São Carlos, 2013. Disponível em:

https://repositorio.ufscar.br/bitstream/handle/ufscar/2645/4951.pdf? sequence=1\&isAllowed= y Acesso em: 20 jun. 2020.

ROLIM, Marcos. A formação de jovens violentos: para uma etiologia da disposicionalidade violenta. 2014. 246f. Tese (Doutorado em Sociologia) - Porto Alegre: Universidade Federal do Rio Grande do Sul, 2014. Disponível em: https://lume.ufrgs.br/handle/10183/102225 Acesso em: 20 jun. 2020.

SÃO PAULO. Lei $\mathbf{n}^{\mathbf{0}}$ 12.469, de 22 de dezembro de 2006. Altera a denominação da Fundação Estadual do Bem-Estar do Menor, e dá providências correlatas, 2006. Disponível em: https://www.al.sp.gov.br/repositorio/legislacao/lei/2006/lei-12469-22.12.2006.html Acesso em: 26 jun. 2020.

SCOLARO, Maria Elvira Nogueira Laranjeira. Escola, para que te quero? Marcas da escola em adolescentes privados de liberdade por prática de ato infracional. 2007. 184f. Dissertação (Mestrado em Educação) - Salvador: Universidade do Estado da Bahia, 2007. Disponível em: http://www.dominiopublico.gov.br/pesquisa/DetalheObraForm.do?select_action=\&co_obra=1 $\underline{30419}$ Acesso em: 20 jun. 2020.

VENÂNCIO, Luciana. O que nós sabemos? Da relação com o saber na e com a educação física em um processo educacional-escolar. 2014. $294 \mathrm{f}$. Tese (doutorado) - Presidente Prudente: Universidade Estadual Paulista Júlio de Mesquita Filho, Faculdade de Ciências e Tecnologia, 2014. Disponível em:

https://repositorio.unesp.br/bitstream/handle/11449/122255/000813226.pdf?seq Acesso em: 20 jun. 2020.

VENÂNCIO, Luciana; BETTI, Mauro; FREIRE, Elisabete Santos; SANCHES NETO, Luiz. Modos de abordar a aprendizagem na educação física escolar: sujeitos interlocutores na relação com o saber. Revista Brasileira de Educação Física Escolar, v. 3, p. 1-11, 2016. Disponível em: https://www.rebescolar.com/Conpefe/modos-de-abordar-a-aprendizagem-naeduca\%c3\%87\%c3\%83o-f\%c3\%8dsica-escolar\%3a-sujeitos-interlocutores-narela\%c3\%87\%c3\%83o-com-o-saber. Acesso em: 20 jun. 2020.

VOLPI, Mario (Org.). O adolescente e o ato infracional. 6ª ed. São Paulo: Cortez, 2006.

ZANELLA, Maria Nilvane. Adolescente em conflito com a lei e escola: uma relação possível? Revista Brasileira Adolescência e Conflitualidade, v.3, p. 4-22, 2010. Disponível em: https://revista.pgsskroton.com/index.php/adolescencia/article/view/239 Acesso em: 20 jun. 2020.

Recebido em: 27 de junho de 2020.

Aprovado em: 27 de agosto de 2020. 